\title{
ANNOTATIONS
}

\section{Blindness and its Prevention}

A remarkable volume of 283 pages has been published by the International Association for the Prevention of Blindness relating to blindness throughout the world and its prevention. It is entitled "The number of the blind and the protection of the eyes in different countries," and may be obtained at the headquarters of the Association, 66, Boulevard Saint-Michel, Paris (VI).

The volume is based on the replies from 35 different countries to a questionnaire sent out two years ago. The replies emanated from Government Departments, and from oculists and others who had access to hospitals and local government reports. They were completed by data suppiied by the International Labour Office of the League of Nations.

The problem of the prevention of blindness is very largely a social and economic problem; it is not exclusively scientific, although it must be approached under the guidance of opthalmologists.

A distinction must be drawn between societies for the welfare of the blind, and committees which deal with the prevention of blindness. It is with the latter only that the present volume is concerned, and the subject is of vital importance to every nation, for it is not only the effect of diseases in the causation of blindness that has to be considered, but also the hazards of industrial occupations. Although in many countries there are regulations for the protection of the eyes of workmen in occupations where harmful liquids, particles and light-rays may do damage, it is often necessary to educate the workmen as to the value of the precautions advised.

The Prevention of Blindness Committee in England (66, Victoria Street, London, S.W.1) and the National Society for the Prevention of Blindness (New York) have each performed important national functions; the former by its collaboration with the Ministry of Health in organising the registration of the blind and the causes of blindness, and the latter by its pervading influence in the United States and by the possession of considerable resources.

By the publication of the present volume the International Association for the Prevention of Blindness has shown that its Executive Committee, and especially the compiler of the present volume, Dr. A. Churchill, have an admirable and practical knowledge of their subject. It is regrettable that their financial resources are so small. It is of real importance that the Association shall 
continue to flourish ; it interferes with no national organisation, it can give advice to newly formed national societies, and it can bring together for international study the different problems with which different countries are confronted.

The prevention of blindness takes an entirely different aspect according to the nature of the country in which it is considered, whether temperate or tropical. In temperate countries such as Great Britain, France, Germany and the greater part of the United States of America the causes of blindness from infectious disease are diminishing, but from industrial eye injuries and refraction errors are increasing. However, in tropical countries the campaign against the causes of blindness is an infinitely more serious and urgent problem. To the severe endemic diseases (infectious conjunctivitis, small-pox, gonorrhoea, trachoma, syphilis) are added the starvation disease, xerophthalmia, and the results of quackery.

The International Association for the Prevention of Blindness had its origin at the XIII Concilium Ophthalmologicum, and therefore among ophthalmologists; however, the necessity of social measures to effect some of the objects of the Association seems to call for the co-operation of sub-committees composed of industrialists and other non-medical members.

Statistics of the number of blind per 100,000 of the population vary from 776 in the case of Egypt, to 32 in the case of New Zealand. When an increase in the proportion of blind appears in statistics it does not necessarily mean that there is any real increase of blindness, but that greater care is taken in the registration of blind persons.

This important report is full of interest; it deserves study by all social workers, as well as by officials of all Ministries of Health, and by all Medical Officers of Health.

\section{Variations on a Theme}

Jaeger 1 may sometimes prove a stumbling block even to those with adequate near vision, and when this occurs the patient may unwittingly be subjecting himself to what is almost a form of psycho-analysis. A paragraph familiar to many ophthalmologists begins with the words "It was upon a delicious summer morning." Several, of the bright young thing type, particularly if they are in their first season, will render this "It was upon a delirious summer evening." A solicitor who specialised in divorce work, read it as "It was upon a delicate matter," whereas a woman who was verging upon religious mania beamed all over her face and read "It was upon a dedication morning." Another paragraph, Jaeger 4 this time, which begins, "I have always suspected 